Article

\title{
Optimal Evacuation Strategy for Parking Lots Considering the Dynamic Background Traffic Flows
}

\author{
Xinhua Mao ${ }^{1,2}, *$, Changwei Yuan ${ }^{1}$, Jiahua Gan ${ }^{3}$ and Jibiao Zhou ${ }^{4,5}$ \\ 1 School of Economics and Management, Chang'an University, Xi'an 710064, China; changwei@chd.edu.cn \\ 2 Department of Civil and Environmental Engineering, University of Waterloo, \\ Waterloo, ON N2L 3G1, Canada \\ 3 Transport Planning and Research Institute, Ministry of Transport, Beijing 100028, China; ganjh@tpri.org.cn \\ 4 School of Civil and Transportation Engineering, Ningbo University of Technology, Ningbo 315211, China; \\ zhoujb2014@nbut.edu.cn \\ 5 College of Transportation Engineering, Tongji University, Shanghai 201804, China \\ * Correspondence: mxinhua@uwaterloo.ca
}

Received: 20 May 2019; Accepted: 19 June 2019; Published: 21 June 2019

\begin{abstract}
An optimal evacuation strategy for parking lots can shorten evacuation times and reduce casualties and economic loss. However, the impact of dynamic background traffic flows in a road network on the evacuation plan is rarely taken into account in existing approaches. This research develops an optimal evacuation model with total evacuation time minimization by dividing the evacuation process in a parking lot into two periods. In the first period, a queuing theory is used to estimate the queuing time, and in the second period, a traffic flow equilibrium model and an intersection delay model are employed to simulate vehicles' route choice. To deal with these models, a modified ant colony algorithm is developed. The results of a numerical example prove that the proposed method has an advantage in improving evacuation efficiency. The results also show that background traffic flows affect not only vehicles' average queuing time in parking lots but also optimal evacuation route choice. Additionally, a sensitivity analysis indicates that the minimum threshold of headway time that allows vehicles out of a parking lot to merge into the background traffic flows on the roads connecting the exits has a great impact on average queuing time, average travel time, and total evacuation time.
\end{abstract}

Keywords: optimal evacuation strategy; parking lot; dynamic background traffic flows; queuing theory; departure rate; average queuing time; average travel time; total evacuation time

\section{Introduction}

Vehicle evacuation refers to the guiding of vehicles gathered at a dangerous place to safe areas within an effective time by traffic control measures when emergencies happen [1]. As an important part of disaster mitigation and emergency disposal, an optimal evacuation management strategy must be made during the evacuation process that comprehensively considers road network capacities, traffic management equipment, emergency response resources, real-time traffic conditions, etc., to reduce casualties and economic losses [2]. Due to the increasing growth of vehicles and emergencies, the vehicle evacuation problem has attracted more and more attention from researchers [3].

The parking lot is a kind of common public infrastructure in cities where a lot of cars usually gather. Hence, an effective vehicle evacuation strategy for emergencies is necessary for the safety and security management of parking lots. To increase vehicles' departure rate, a single parking lot is usually designed with more than one exit connecting multiple roads [4], which makes evacuation both a multi-origin and multi-destination problem. In the actual evacuation process of a parking lot, traffic 
capacity and delay on every road in the network change over time, and they are dependent on both background traffic flows and evacuation traffic flows. However, most traditional vehicle evacuation models ignore the dynamics of background traffic flows [5-7]. The impact of background traffic flows on evacuation strategy, including the queue of vehicles in a parking lot and the choice of optimal routes in the evacuation road network, has rarely been investigated, which should be taken into consideration in optimal vehicle evacuation modeling. Additionally, a comprehensive and accurate estimation of total evacuation time has not been completely investigated [8].

To fill this gap, we have divided the whole evacuation process for a parking lot into two periods. For the first period, we have developed a queuing model that considers the impact of background traffic flow on vehicles' departure rate-thus allowing for the estimation of the average queuing time of vehicles in parking lots $[9,10]$. For the second period, we have employed a traffic flow equilibrium model and an intersection delay model to simulate optimal evacuation routes, which also helps calculate travel time and estimate delays at intersections under traffic signal control [11,12]. For the better generation of optimal evacuation strategies for parking lots, this research extends the general approach in three aspects: (i) It formulates the total evacuation time function including the queuing time, the travel time, and the delay at intersections based on the two-period simulation; (ii) it develops an optimal evacuation model for parking lots with total evacuation time minimization; and (iii) it proposes a modified ant colony algorithm as the model solution.

This research makes the following two contributions. Firstly, we develop a queuing model at a parking lot affected by the time headway of background traffic flow on the roads-thus allowing for the estimation of the average queuing time of vehicles in parking lots. Secondly, we propose a framework with minimum evacuation times to generate optimal vehicle evacuation strategies for parking lots, considering the dynamics of background traffic flows.

The remainder of this paper is organized as follows. Section 2 reviews the studies on vehicle evacuation modeling. Section 3 gives the assumptions, proposes the methodology framework in detail, and develops a modified ant colony algorithm as the model solution. Section 4 describes a numerical example and presents the simulation results. Section 5 makes a discussion on the key results obtained from the model and performs a sensitivity analysis. Section 6 draws the main conclusions.

\section{Literature Review}

Vehicle evacuation problems have attracted tremendous attention from researchers [13-15]. In the existing literature, a wide range of modeling approaches have been developed, and these can be classified into two categories: (i) The analytical approach and (ii) the simulation-based approach.

The analytical approach aims to obtain optimal evacuation plans including the shortest evacuation time, the best evacuation routes, and the optimal allocation of evacuees. For example, Sheffi et al. developed a macro model with minimum network clearance time which can simulate traffic patterns during an emergency evacuation [16]. To obtain the shortest evacuation time, Yamada described a minimal cost flow model that considers the traffic capacity limit of a road network [17]. However, these two models are based on static road networks which assume that traffic parameters, e.g., traffic density and traffic volume, are constant values that do not vary during an emergency evacuation process. Since traffic characteristics usually have time-dependent changes, the static road network-based approach has limitations in highly accurate simulations. To fill this gap, many other researchers developed evacuation models based on the dynamic road network which take the time into account and make the best of the performance of the entire network system. For instance, Cova and Johnson formulated an evacuation in a complex road network as an integer extension of the minimum-cost flow problem, which was solved by a mixed-integer programming model [18]. To obtain the optimal evacuation route in a hierarchical directed network, Fang et al. developed a multi-objective optimization model aiming at minimum evacuation time, evacuation distance, and congestion degrees [19]. Sbayti and Mahmassani proposed a modified system-optimal dynamic traffic assignment model with road network clearance time minimization to obtain evacuation trips; this model 
took the delays between origins and destinations into consideration [20]. Based on the above network optimization methods, some uncertainties were also captured in the evacuation models. For example, Bretschneider and Kimms put forward a mixed-integer evacuation model with a minimization of evacuation time which considered the uncertainties of conflicts within intersections [21]. Additionally, other researchers employed a cell-transmission model as an analytical approach to investigate the evacuation problem. Chiu and Zheng employed a cell transmission model-based linear-programming model with simultaneous mobilization strategies which addressed the evacuation plan in a network with different destinations [22]. Likewise, Tak et al. utilized an agent-based cell transmission model to deal with evacuation decisions on destinations and travel directions [23].

The simulation-based approach is another technique used to deal with evacuation problems using traffic assignment simulation models. Murray-Tuite and Mahmassani developed a two-stage evacuation model utilizing a micro assignment simulation procedure to mimic the resulting traffic interactions in a road network [24]. Lämmel et al. presented a robust and flexible simulation framework to predict the evacuation process in a large scale road network [25]. Balakrishna et al. also proposed an adaptive simulation framework for evacuation modeling in different emergent situations [26]. An effective optimization-based simulation procedure was defined by Kimms and Maassen to obtain the optimal routes during an emergency situation in urban areas [27].

Despite the wide range of evacuation modeling approaches, it is rare in literature to incorporate dynamic background traffic flow into evacuation strategy modeling. This research proposes an optimal vehicle evacuation model for parking lots using a road traffic flow equilibrium model and an intersection delay model combined with a queuing model to consider the interaction between dynamic background traffic flow and queuing time. Only in this way can the total time consumption during the evacuation process be evaluated accurately and comprehensively. Furthermore, a modified ant colony algorithm is developed to solve the model.

\section{Materials and Methods}

\subsection{Assumptions}

For simplicity, the following assumptions are given in this section.

(1) Each exit of the modelled parking lot connects only one road.

(2) Each exit of the parking lot has one lane, which only serves one vehicle at the same time.

(3) The evacuation process will not lead to traffic paralysis in the road network.

(4) The vehicle traffic flows on the road network will not be disturbed by non-motor vehicles or pedestrians.

(5) Vehicles evacuated from the parking lot enter into the road network only by a right turn.

\subsection{Two Periods of the Evacuation Process in a Parking Lot}

The vehicle evacuation process in the parking lot can be divided into two periods, as shown in Figure 1.

In the first period-i.e., the time between when a vehicle is generated and when a vehicle is actually loaded onto the road-vehicles have to queue and wait for departure in the parking lot because the traffic capacity of the network usually cannot afford the rapid growth of the traffic need caused by an emergency evacuation.

In the second period-i.e., the time between when vehicles merge into the traffic flows in the road network and when the vehicles reach their final destinations-traffic flows are constituted of background traffic flows and evacuation traffic flows, and the two kinds of traffic flows interact with each other. 
Hence, the background traffic flows in the network not only affect vehicles' queuing time in the parking lot but also determine vehicles' optimal evacuation route choice. In view of this, dynamic background traffic flows should be considered for the optimal evacuation strategy of the parking lot.

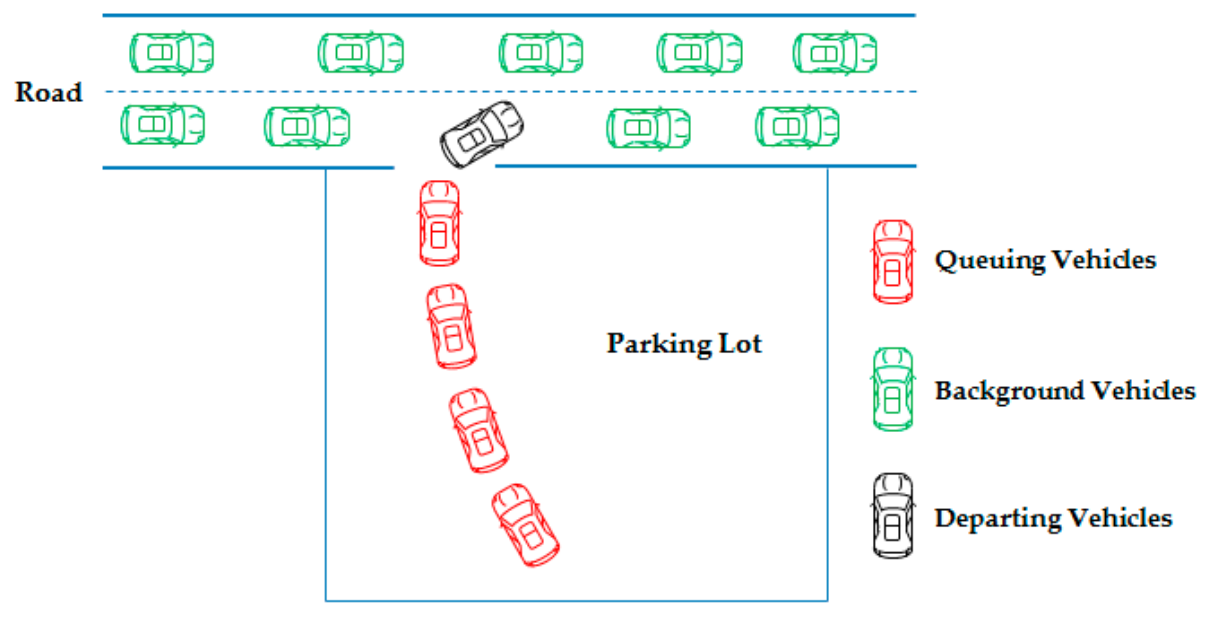

Figure 1. Vehicle evacuation process in a parking lot.

\subsection{Queuing Modeling in the Parking Lot (the First Period)}

Assume that there are $A$ vehicles in the parking lot, which has $R$ exits. When the evacuation begins, vehicles will randomly choose to queue at any exit waiting to leave, which generates $R$ queues in the parking lot, shown in Figure 2. We define the queue at the exit $r$ as queuing system $r, r=1,2, \cdots, R$.

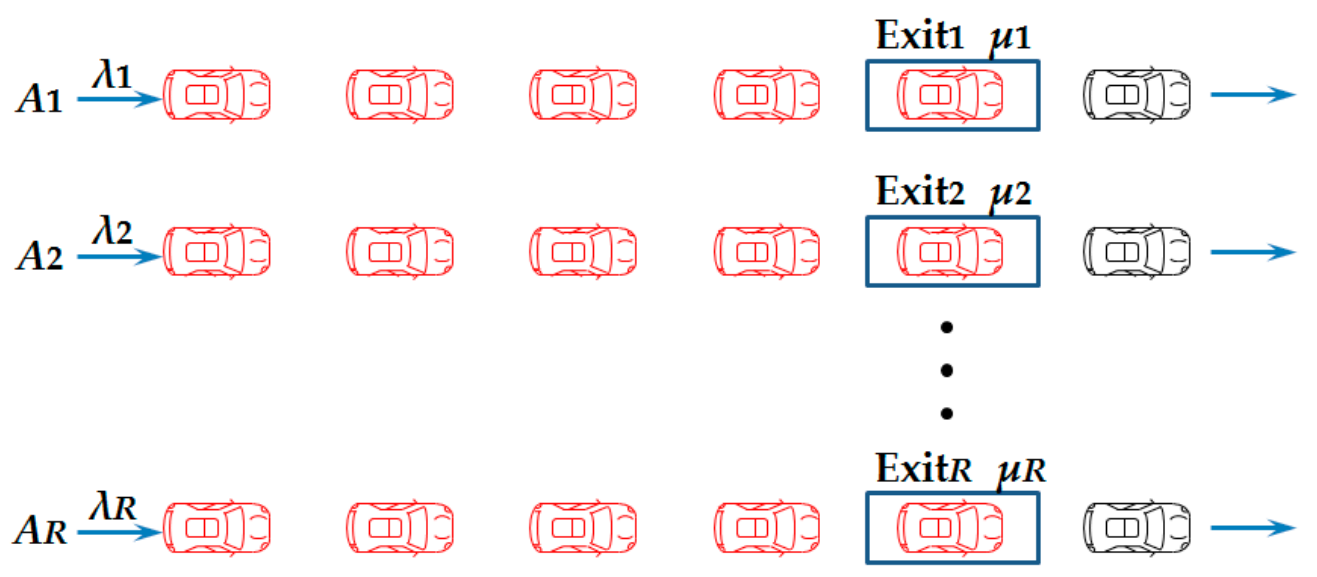

Figure 2. Queuing in a parking lot with $R$ exits.

According to this queuing theory, the queue at any single exit of the parking lot can be denoted as a $\mathrm{M} / \mathrm{M} / 1 / 1$ queuing system [28]. M/M stands for Poisson arrivals and the negative, exponentially distributed lengths of stay [29]; 1/1 indicates that there is only 1 exit which can only serve 1 vehicle at a time [30]. The average queuing time (including waiting time and service time) of queuing system $r$ is calculated as in [31].

$$
\bar{d}_{r}=\frac{1}{\mu_{r}-\lambda_{r}}, \forall r \in R
$$

where $\bar{d}_{r}$ is the average queuing time of queuing system $r ; \mu_{r}$ is the average arrival rate of queuing system $r$, which is the reciprocal of the average time between the arrivals of two consecutive vehicles; and $\lambda_{r}$ is the vehicle departure rate of queuing system $r$, which is the reciprocal of the service time.

However, for a parking lot, the service time $1 / \lambda_{r}$ actually means the period from the time a vehicle arrives at the front of the queue until it merges into the traffic flow on the road connecting the exit $r$, a 
period determined by the background traffic flow. The derivation process of $1 / \lambda_{r}$ is described in detail as follows.

The background traffic volume on the road connecting $r$ th exit of the parking lot is represented by $Q_{r}$ (vehicle/s); the minimum threshold of time headway (interval between two consecutive vehicles) of the background traffic allowing the vehicles out of the exit $r$ to merge into the background traffic is $\tau_{r}$. Hence, the possibility that a single vehicle can merge into the background traffic flow, i.e., the possibility that the time headway $h$ of the background traffic flow is more than $\tau_{r}$, is formulated as in [32].

$$
P_{r}\left(h>\tau_{r}\right)=e^{-Q_{r} \cdot \tau_{r}}, \forall r \in R
$$

where $P_{r}\left(h>\tau_{r}\right)$ is the possibility that the time headway $h$ on the road connecting $r$ th exit of the parking lot is more than $\tau_{i}$.

Accordingly, during the time period $t$, the number of intervals $\left(h>\tau_{r}\right)$ of the background traffic flow is calculated as.

$$
N_{\text {interval }}\left(h>\tau_{r}\right)=Q_{r} \cdot t \cdot e^{-Q_{r} \cdot \tau_{r}}, \forall r \in R
$$

The number of vehicles between two intervals is

$$
N_{\text {vehicle }}=\frac{Q_{r} \cdot t}{Q_{r} \cdot t \cdot e^{-Q_{r} \cdot \tau_{r}}}=e^{Q_{r} \cdot \tau_{r}}, \forall r \in R
$$

The average time between two consecutive intervals is formulated as

$$
T_{r}=\left(e^{Q_{r} \cdot \tau_{r}}-1\right) \times\left(\frac{1}{Q_{r}}-\frac{e^{-Q_{r} \cdot \tau_{r}}}{1-e^{-Q_{r} \cdot \tau_{r}}}\right)=\frac{1-e^{-Q_{r} \cdot \tau_{r}}}{e^{-Q_{r} \cdot \tau_{r}}} \times\left(\frac{1}{Q_{r}}-\frac{e^{-Q_{r} \cdot \tau_{r}}}{1-e^{-Q_{r} \cdot \tau_{r}}}\right)=\frac{1}{Q_{r} \cdot e^{-Q_{r} \cdot \tau_{r}}}-\frac{1}{Q_{r}}-\tau_{r}, \forall r \in R
$$

Since the vehicle at the front of the queuing system $r$ can only leave and merge into the background traffic flow when $h>\tau_{r}$, the average time between the two intervals can be denoted as the service time of the queuing system $r$.

$$
\frac{1}{\lambda_{r}}=T_{r}=\frac{1}{Q_{r} \cdot e^{-Q_{r} \cdot \tau_{r}}}-\frac{1}{Q_{r}}-\tau_{r}, \forall r \in R
$$

Accordingly, Equation (1) can be rewritten as Equation (7).

$$
\bar{d}_{r}=\frac{1}{\mu_{r}-\frac{1}{T_{r}}}=\frac{T_{r}}{\mu_{r} \cdot T_{r}-1}=\frac{e^{Q_{r} \cdot \tau_{r}}-Q_{r} \cdot \tau_{r}-1}{\mu_{r} \cdot\left(e^{Q_{r} \cdot \tau_{r}}-Q_{r} \cdot \tau_{r}-1\right)-Q_{r}}, \forall r \in R
$$

As a result, the sum of all vehicles' queuing time in the parking lot is calculated as

$$
\mathrm{T}_{Q}=\sum_{r=1}^{R} A_{r} \cdot \bar{d}_{r}
$$

where $T_{Q}$ is the sum of all vehicles' queuing time in the parking lot and $A_{r}$ is the number of vehicles in the queuing system $r$, which should be subject to

$$
\sum_{r=1}^{R} A_{r}=A
$$

\subsection{Network Traffic Flow Modeling (the Second Period)}

The second period of the evacuation process for a parking lot with multiple exits can be described as a multi-origin and multi-destination evacuation problem [33]. We represent a multi-origin and multi-destination evacuation network in Figure 3, where vehicles are evacuated from origins $V_{1}$ through mid-points $V_{2}$ to destinations $V_{3}$. 

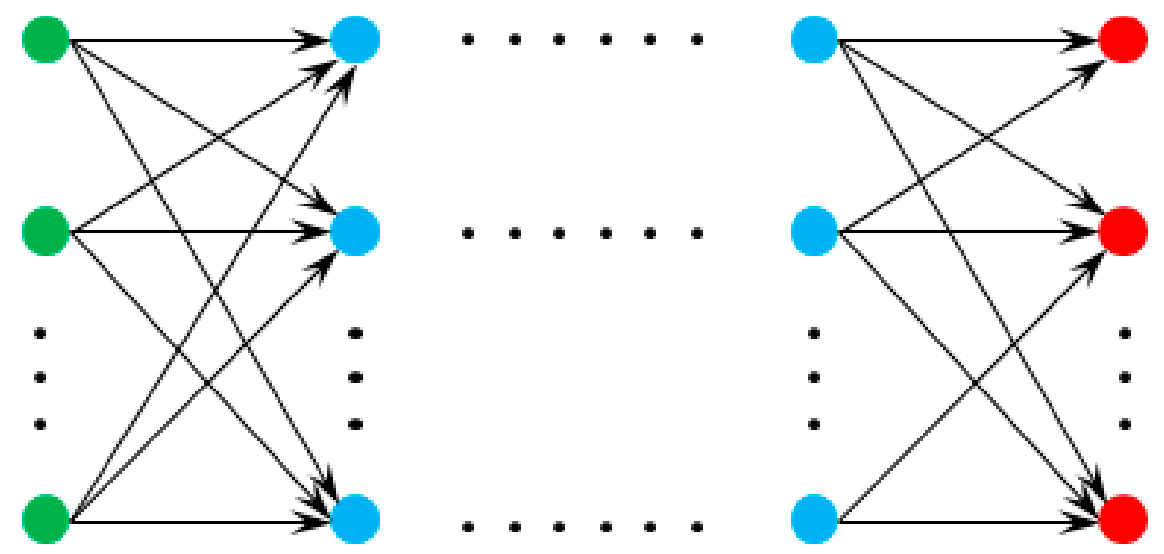

Figure 3. An evacuation network with multi-origin and multi-destination.

\subsubsection{Traffic Flow Equilibrium Modeling on Nodes}

Inspired by the network traffic flow theory, for every mid-point in an evacuation network, equilibrium can be achieved between the total inflow traffic (including background traffic and evacuation traffic) and the outflow traffic [34]. This is formulated as

$$
\sum_{i=1}^{N}\left(q_{i j}+q_{i j}^{*}\right)-\sum_{i=1}^{N}\left(q_{j i}+q_{j i}^{*}\right)=0, \forall i, j \in V_{2}
$$

Additionally, the total evacuation traffic generated by the origins equals the total evacuation traffic attracted by destinations. This is described as

$$
\sum_{s=1}^{M} q_{s j}-\sum_{g=1}^{U} q_{j g}=0, \forall j \in V_{2}, \forall s \in V_{1}, \forall g \in V_{3}
$$

\subsubsection{Evacuation Traffic Equilibrium Modeling on Links}

According to the trip distribution theory, the traffic flow distribution in the network is determined by the traffic demands between the origins and destinations [35]. Hence, the evacuation traffic equilibrium is formulated as

$$
\begin{gathered}
\sum_{k \in K_{s g}} h_{k}^{s g}=Q_{s g}, \forall s \in V_{1}, \forall g \in V_{3} \\
\sum_{k \in K_{s g}} \sum_{s \in V_{1}} \sum_{g \in V_{3}} h_{k}^{s g} \cdot \delta_{i j}^{s g, k}=q_{i j}, \forall i, j \in V_{1} \cup V_{2} \cup V_{3}
\end{gathered}
$$

where Equation (12) is the evacuation traffic conservation which indicates the evacuation demands from origin $s$ to destination $g$ is the sum of evacuation traffic flows on all routes connecting origin $s$ to destination $g$ [36]. Equation (13) indicates that the evacuation traffic flow on every single link is the sum of evacuation traffic flows on all routes on which the link lies [37]. 


\subsubsection{Travel Time on Links}

The travel time on links is affected by actual traffic flow. We use Equation (14), as in [38], to establish the travel time function related to traffic flows.

$$
t_{i j}\left(q_{i j}+q_{i j}^{*}\right)=\frac{l_{i j}}{v_{i j 0}} \cdot\left(1+\psi \cdot\left(\frac{q_{i j}+q_{i j}^{*}}{c_{i j}}\right)^{\xi}\right)
$$

Hence, the total travel time of all vehicles evacuated is calculated as

$$
T_{T}=\sum_{i, j}^{N} \sum_{k \in K_{s g}} \delta_{i j}^{s g, k} \cdot \int_{0}^{q_{i j}} t_{i j}(x) d x, \forall i, j \in V_{1} \cup V_{2} \cup V_{3}
$$

\subsection{Simulation of Intersection Delay under Signal Control}

We use the approach as in [39] to simulate the intersection delay under signal control. This is formulated as.

$$
\bar{D}_{i j}=\frac{\mu(1-\lambda)^{2}}{2(1-\lambda y)}+\frac{y^{2}}{2\left(q_{i j}+q_{i j}^{*}\right) \cdot(1-y)}-\omega \cdot\left(\frac{\mu}{\left(q_{i j}+q_{i j}^{*}\right)^{2}}\right)^{\frac{1}{3}} \cdot y^{(2+\lambda 5)}
$$

where $\bar{D}_{i j}$ is the average delay at the intersection $j$ on the route $(i, j), \mu$ is the signal cycle time, $\lambda$ is the green time ratio, $y$ is the degree of saturation, and $\omega$ is a field calibration coefficient.

Hence, the total intersection delays $T_{D}$ of all vehicles on their evacuation routes are calculated as

$$
T_{D}=\sum_{i, j}^{N} \sum_{k \in K_{s g}} \delta_{i j}^{s g, k} \cdot q_{i j} \cdot \bar{D}_{i j}, \forall i, j \in V_{1} \cup V_{2} \cup V_{3}
$$

\subsection{Optimal Evacuation Modeling}

$$
\text { Minimize } T=T_{Q}+T_{T}+T_{D}
$$

Subject to the constraints

$$
\begin{gathered}
\sum_{i=1}^{N}\left(q_{i j}+q_{i j}^{*}\right)-\sum_{i=1}^{N}\left(q_{j i}+q_{j i}^{*}\right)=0, \forall i, j \in V_{2} \\
\sum_{s=1}^{M} q_{s j}-\sum_{g=1}^{U} q_{j g}=0, \forall j \in V_{2}, \forall s \in V_{1}, \forall g \in V_{3} \\
\sum_{k \in K_{s g}} h_{k}^{s g}=Q_{s g}, \forall s \in V_{1}, \forall g \in V_{3} \\
\sum_{k \in K_{s g}} \sum_{s \in V_{1}} \sum_{g \in V_{3}} h_{k}^{s g} \cdot \delta_{i j}^{s g, k}=q_{i j}, \forall i, j \in V_{1} \cup V_{2} \cup V_{3} \\
\sum_{s \in V_{1}} \sum_{g \in V_{3}} Q_{s g}=A \\
0 \leq q_{i j}+q_{i j}^{*} \leq c_{i j}, \forall i, j \in V_{1} \cup V_{2} \cup V_{3}
\end{gathered}
$$




$$
h_{k}^{s g} \geq 0, \forall k \in K_{\text {st }}
$$

where Equation (18) is the objective function which ensures total evacuation time minimization including queuing time, travel time, and intersection delay; Equations (19) and (20) are traffic flow equilibrium constraints on nodes; Equations (21) and (22) are traffic flow equilibrium constraints on links; Equation (23) means that the sum of the evacuation demands from all origins to destinations is equal to the vehicles in the parking lot; Equation (23) is the traffic capacity constraint; and Equation (24) makes sure that the traffic flow on every single route is nonnegative.

\subsection{Model Solution}

An ant colony algorithm is a common method to solve optimization problems which has advantages such as a strong robustness and a great global searching ability [40,41]. However, it has a slow convergence rate and a poor local searching ability [42,43]. Hence, we developed a modified ant colony algorithm to solve the optimal evacuation model proposed above. The modification was made to focus on the strategy of pheromone updating and the formulation of a heuristic function. The detailed steps of the algorithm are as follows.

Step 1: Initialization. Denote the initial number of iterations $N_{\text {iteration }}=0$; set the initial value of the pheromone on every link to $\vartheta_{i j}(0)$ and $\Delta \vartheta_{i j}=0$; and set the number of ants to $m$.

Step 2: Start the iteration. Set $N_{\text {iteration }}=N_{\text {iteration }}+1$. Ant $k(k=1,2, \cdots, m)$ chooses its route based on the pheromone of each link. The possibility for ant $k$ to determine the direction of its transition from node $i$ to node $j$ at time $t$ is formulated as

$$
\begin{gathered}
P_{i j}^{k}(t)=\left\{\begin{array}{cc}
\frac{\vartheta_{i j}^{\alpha}(t) \cdot \eta_{i j}^{\beta}(t)}{\sum_{p \in \text { allowed }_{k} \vartheta_{i p}^{\alpha}(t) \cdot \eta_{i p}^{\beta}(t)}} & j \in \text { allowed }_{k} \\
0 & \text { otherwise }
\end{array}\right. \\
\eta_{i j}(t)=\frac{1}{t_{i j}+\bar{D}_{i j}}
\end{gathered}
$$

where $P_{i j}^{k}(t)$ is the possibility for ant $k$ to determine the direction of its transition from node $i$ to node $j$ at time $t ; \vartheta_{i j}(t)$ is the value of the pheromone on link $(i, j)$ at time $t ; \eta_{i j}(t)$ is a heuristic function on link $(i, j)$ which is the reciprocal of the sum of travel time $t_{i j}$ and intersection delay $\bar{D}_{i j}$ on link $(i, j) ;$ allowed $_{k}$ is a dynamic node set which represents the nodes that ant $k$ can choose for its next transition; $p$ is the node that ant $k$ can choose for its next transition, $p \in$ allowed $_{k}$; and $\alpha$ is a heuristic information factor which is defined as the role of ant's accumulative information in its route selection. The higher the value of $\alpha$ is, the more inclined the ant is to choose the route passed by other ants. Finally, $\beta$ is the heuristic factor of expectation which indicates the importance of heuristic information in ant's route selection. The greater the value of $\beta$ is, the higher the possibility of the transition is.

Additionally, a tabu table $t a b u_{k}$ is created to record the routes of ant $k$.

Step 3: If every single ant finds a feasible route, the shortest path in time is identified as the optimal route obtained by this iteration. Otherwise, return to Step 2 and execute the procedure until all ants find their feasible routes.

Step 4: Pheromone update. The pheromone on every link is updated after every ant finishes its ergodic operation. In this research, we updated the pheromone according to the following principles.

$$
\begin{gathered}
\vartheta_{i j}(t+1)=(1-\rho) \cdot \vartheta_{i j}(t)+\Delta \vartheta_{i j}(t) \\
\Delta \vartheta_{i j}(t)=\sum_{k=1}^{m} \Delta \vartheta_{i j}^{k}(t)
\end{gathered}
$$


where $\rho$ is the pheromone volatilization coefficient which belongs to $(0,1), \Delta \vartheta_{i j}(t)$ is the pheromone change on the link $(i, j)$, and $\Delta \vartheta_{i j}^{k}(t)$ is the pheromone left on the link $(i, j)$ by the $k$ th ant. $\Delta \vartheta_{i j}^{k}(t)$ is calculated by Equation (30).

$$
\Delta \vartheta_{i j}^{k}(t)=\left\{\begin{array}{cc}
\eta_{i j}^{k}(t) & \text { If the } k \text { th ant goes along the route }(i, j) \\
0 & \text { Otherwise }
\end{array}\right.
$$

where $\eta_{i j}^{k}(t)$ is the reciprocal of the sum of the $k$ th ant's travel time and intersection delay on link $(i, j)$.

Step 5: Repeat the procedure from steps 2 to 4 until $N_{\text {iteration }}$ iterations are completed.

\section{Numerical Example}

A city parking lot in Xi'an, a city of western China, was employed to test the approach framework proposed in this research. The layout of the road network is plotted in Figure 4. We assumed that a maintenance action would be conducted to the parking lot at 2:00 p.m. on Friday when there would be 860 vehicles in the parking lot. In order to prevent serious traffic congestion in the road network, these vehicles would have to be evacuated two kilometers away from the parking lot, i.e., the vehicles would have to be evacuated to the area other than a circle with a diameter of two kilometers. The area inside the circle was defined as a dangerous area, while the area outside the circle was the safe area.

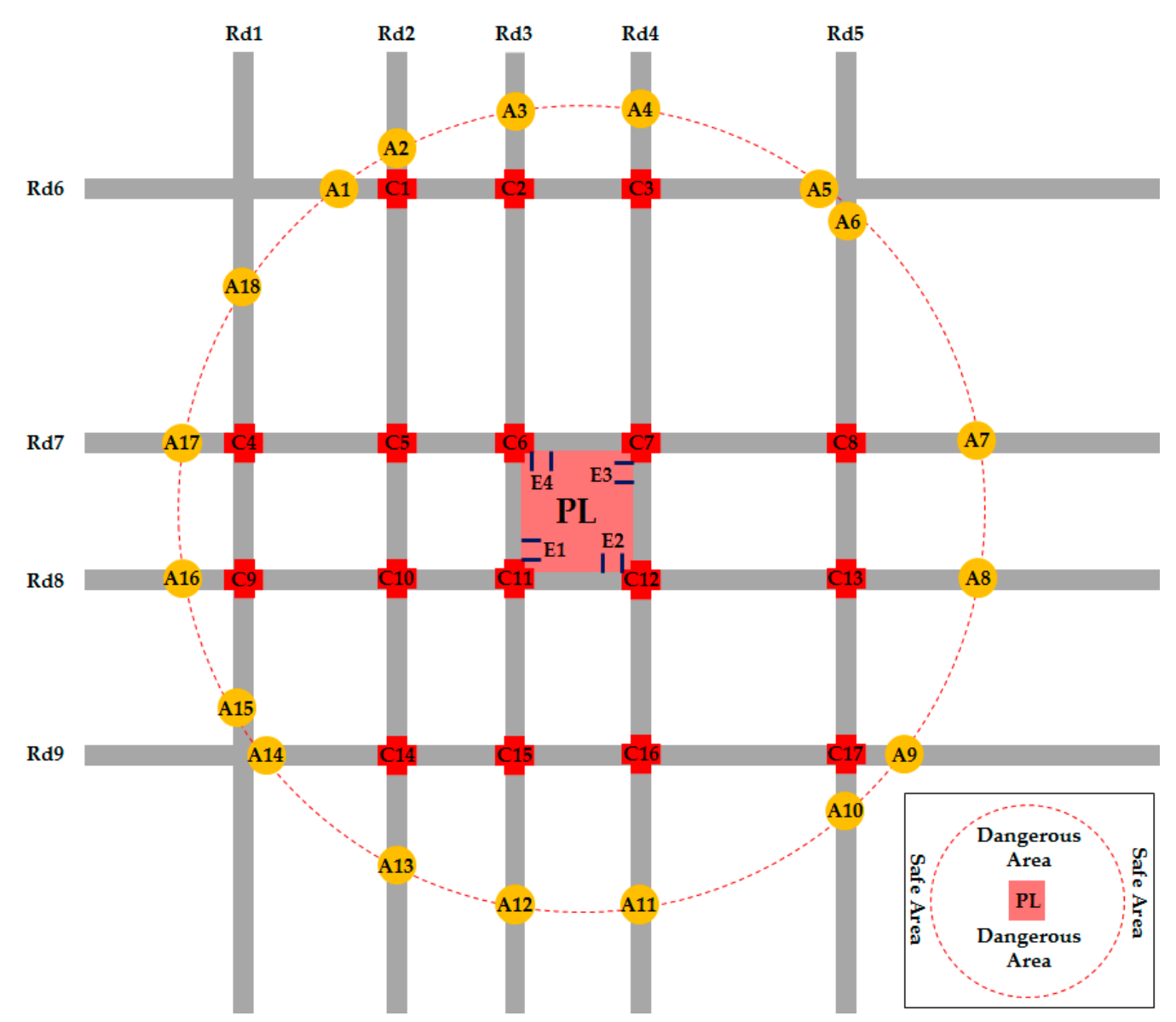

Figure 4. Configuration of the parking lot and road network layout.

In this numerical example, four exits of the parking lot $V_{1}=\{E 1, E 2, E 3, E 4\}$ were denoted as the set of origins of evacuation routes; $V_{2}=\{C 1, C 2, \cdots, C 17\}$ were denoted as the set of mid-points of evacuation routes; and $V_{3}=\{A 1, A 2, \cdots, A 15\}$ were defined as the set of destinations of evacuation routes. 


\subsection{Data Collection}

The network constituted nine roads and 17 intersections. We collected the length, traffic capacity, the free flow speed of each road segment. The traffic volumes on all road segments between two intersections were also collected every five minutes from 13:00 to 14:00 and transferred back to the laboratory in real time. The data of the road network and traffic volumes are shown in Appendix A, Table A1.

The 17 intersections were all controlled by traffic signal systems. The signal cycle time and green time ratio of each traffic signal system were collected, as is shown in Table 1 . The degree of saturation at each entrance of every intersection was also captured in real time.

Table 1. Parameters of each traffic signal systems at the intersections.

\begin{tabular}{cccccc}
\hline Intersection & $\begin{array}{c}\text { Signal Cycle } \\
\text { Time (s) }\end{array}$ & $\begin{array}{c}\text { Green } \\
\text { Time Ratio }\end{array}$ & Intersection & $\begin{array}{c}\text { Signal Cycle } \\
\text { Time (s) }\end{array}$ & $\begin{array}{c}\text { Green } \\
\text { Time Ratio }\end{array}$ \\
\hline C1 & 145 & 0.42 & $\mathrm{C} 10$ & 125 & 0.45 \\
C2 & 140 & 0.42 & $\mathrm{C} 11$ & 106 & 0.46 \\
C3 & 130 & 0.48 & $\mathrm{C} 12$ & 144 & 0.41 \\
C4 & 138 & 0.50 & $\mathrm{C} 13$ & 138 & 0.43 \\
C5 & 140 & 0.41 & $\mathrm{C} 14$ & 125 & 0.46 \\
C6 & 135 & 0.45 & $\mathrm{C} 15$ & 125 & 0.46 \\
C7 & 120 & 0.45 & $\mathrm{C} 16$ & 142 & 0.37 \\
C8 & 118 & 0.48 & $\mathrm{C} 17$ & 135 & 0.34 \\
C9 & 122 & 0.50 & & & \\
\hline
\end{tabular}

\subsection{Results}

The evacuation problem was simulated using MATLAB R2018b (version 11.4) software (MathWorks, Natick, MA, USA). The parameters are shown in Table 2.

Table 2. Parameter settings.

\begin{tabular}{cccccc}
\hline Parameters & Value & Parameters & Value & Parameters & Value \\
\hline$\mu_{r}$ & $3 \mathrm{~s}$ & $\xi$ & 2.82 & $m$ & 30 \\
$\tau_{r}$ & $6 \mathrm{~s}$ & $\omega$ & 0.65 & $\alpha$ & 0.5 \\
$v_{i j 0}$ & $80 \mathrm{~km} / \mathrm{h}$ & $N_{\text {iteration }}$ & 70 & $\beta$ & 0.5 \\
$\psi$ & 0.48 & $\vartheta_{i j}(0)$ & 20 & $\rho$ & 0.2 \\
\hline
\end{tabular}

\subsubsection{Optimal Evacuation Routes}

We obtained an optimal evacuation plan from the outcome of the model, shown in Table 3. During the whole evacuation process, due to the background traffic flows in the road network, different amounts of vehicles were evacuated through the four exits of the parking lot, i.e., 216 vehicles are evacuated through exit E1 to destinations (A1, A2, A3, A17, and A18) along five routes; 264 vehicles were evacuated through exit E2 to destinations (A12, A13, A14, A15, and A16) along five routes; 196 vehicles were evacuated through exit E3 and followed four routes to their destinations (A8, A9, A10, and A11); 184 vehicles were evacuated through exit E4 and followed four routes to the destinations (A4, A5, A6, and A7). Figure 5 reveals the total number of vehicles evacuated along different optimal routes from the four exits. We also know that the vehicles evacuated were inclined to choose the fastest route other than the shortest route. 
Table 3. Optimal evacuation routes.

\begin{tabular}{cccccc}
\hline Original Node & $\begin{array}{c}\text { Destination } \\
\text { Node }\end{array}$ & Route & Route ID & $\begin{array}{c}\text { Total Vehicles } \\
\text { Evacuated }\end{array}$ & Length (km) \\
\hline \multirow{5}{*}{ E1 } & A1 & E1-C6-C5-C1-A1 & R1 & 28 & 4.8 \\
& A2 & E1-C6-C2-C1-A2 & R2 & 34 & 4.7 \\
& A3 & E1-C6-C2-A3 & R3 & 59 & 4.4 \\
& A17 & E1-C6-C5-C4-A17 & R4 & 51 & 3.3 \\
& A18 & E1-C6-C5-C4-A18 & R5 & 44 & 4.3 \\
\hline \multirow{5}{*}{ E2 } & A12 & E2-C11-C15-A12 & R6 & 62 & 4.4 \\
& A13 & E2-C11-C15-C14-A13 & R7 & 53 & 4.5 \\
& A14 & E2-C11-C10-C14-A14 & R8 & 47 & 4.4 \\
& A15 & E2-C11-C10-C9-A15 & R9 & 31 & 3.9 \\
E3 & A16 & E2-C11-C10-C9-A16 & R10 & 71 & 3 \\
& A8 & E3-C12-C13-A8 & R11 & 61 & 4.2 \\
& A9 & E3-C12-C13-C17-A9 & R12 & 46 & 5.1 \\
& A10 & E3-C12-C16-C17-A10 & R13 & 35 & 4.9 \\
A11 & E3-C12-C16-A11 & R14 & 54 & 4.3 \\
\hline \multirow{5}{*}{ E4 } & A4 & E4-C7-C3-A4 & R15 & 49 & 4.1 \\
& A5 & E4-C7-C3-A5 & R16 & 54 & 5.4 \\
& A6 & E4-C7-C8-A6 & R17 & 30 & 5.3 \\
& A7 & E4-C7-C8-A7 & R18 & 51 & 4.1 \\
\hline
\end{tabular}

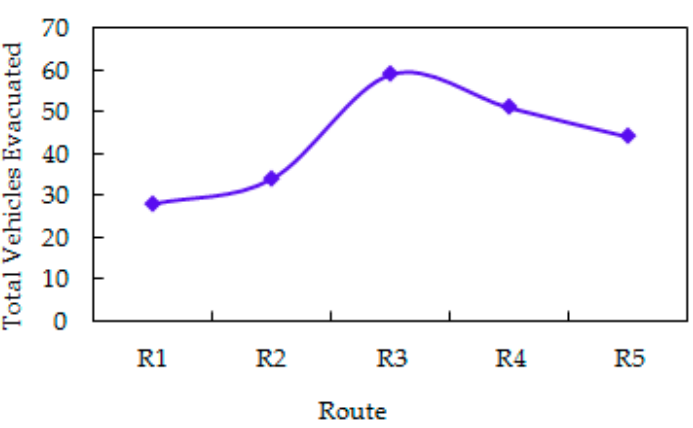

(a)

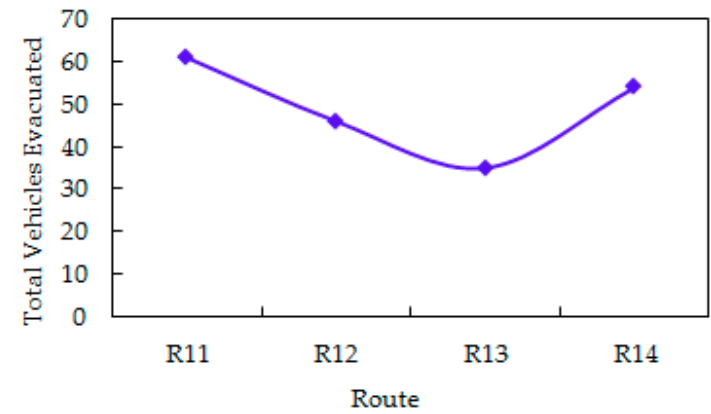

(c)

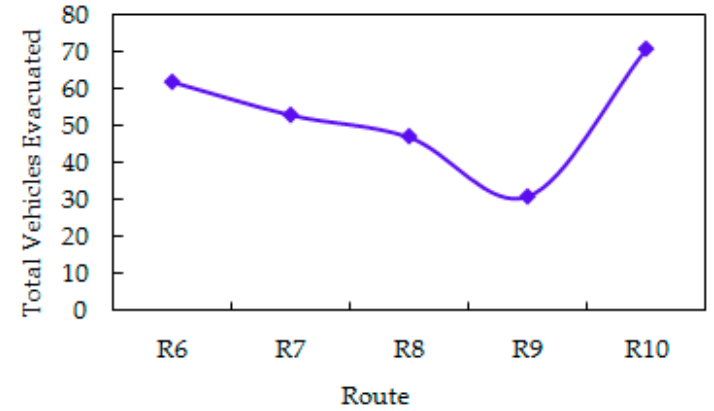

(b)

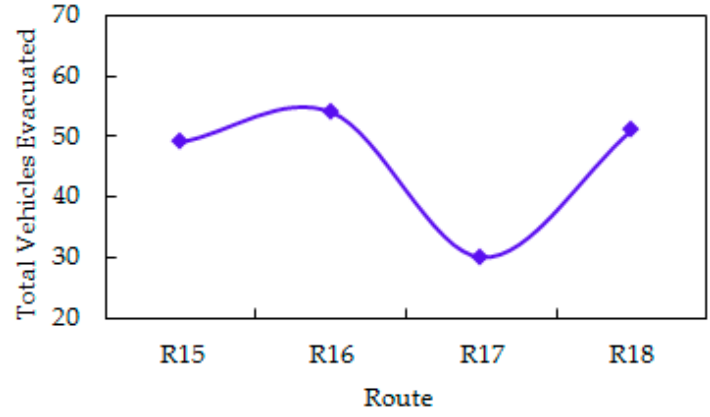

(d)

Figure 5. Total vehicles evacuated along different optimal routes from the four exits of the parking lot. (a) Exit E1. (b) Exit E2. (c) Exit E3. (d) Exit E4.

The standard deviation of the number of vehicles evacuated on each route is 11.8, which means there were differences in the number of vehicles evacuated on each of the 18 routes, i.e., there was an inequality of spatial distribution of vehicle evacuation. 


\subsubsection{Dynamic Evacuation Process}

Vehicle evacuation for a parking lot is a dynamic process, i.e., the vehicle departure rate in a parking lot has a dynamic time-variation, and vehicles choose their optimal routes dynamically because of the dynamic background traffic flows in the road network. Departure curves plotted in Figure 6 display the cumulative vehicles evacuated through the four exits of the parking lot to their destinations along all routes at different times during the evacuation process.

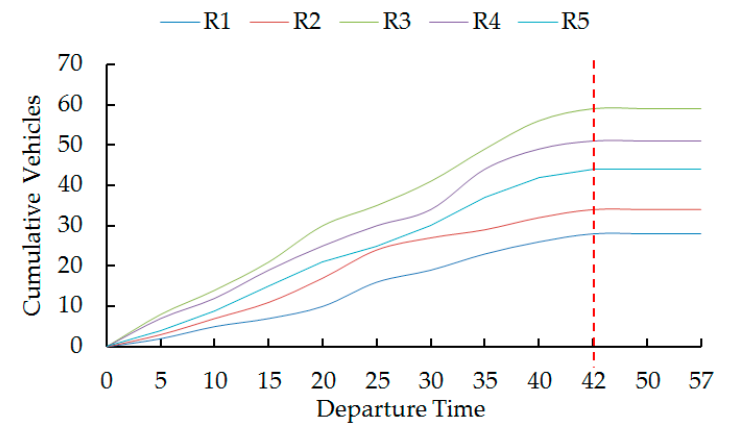

(a)

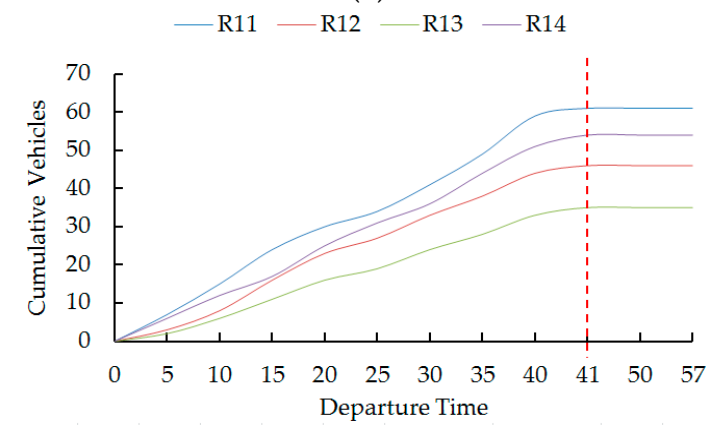

(c)

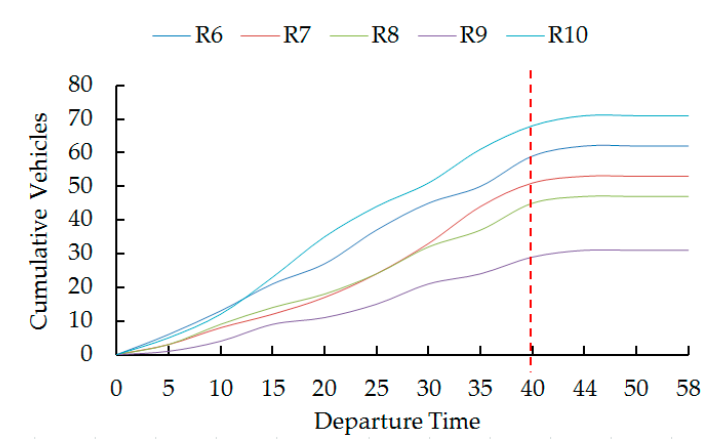

(b)

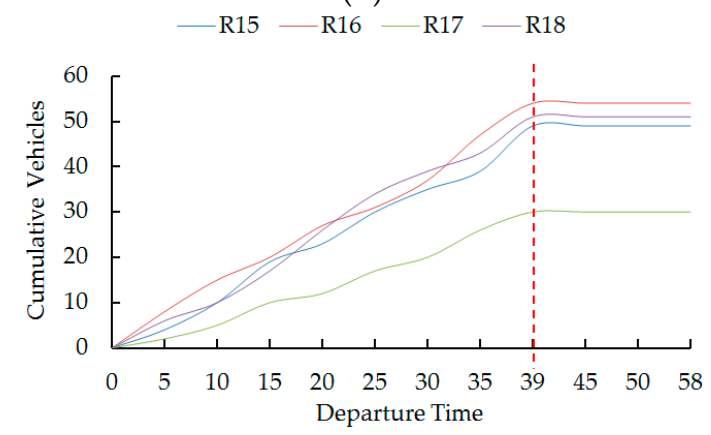

(d)

Figure 6. Dynamic evacuation process from the four exits of the parking lot. (a) Exit E1. (b) Exit E2. (c) Exit E3. (d) Exit E4.

It was found that, according to the variation of background traffic flows, each exit of the parking lot generated different numbers of vehicles that selected their optimal routes dynamically. For example, all four exits generated 80 vehicles during the first five minutes, but they generated 112 vehicles during the third five minutes. Three vehicles were evacuated along route A13 during the first five minutes, but 11 vehicles were generated during the seventh five minutes.

We also find that it took 42 minutes for exit E1 to clear all 216 vehicles, 40 minutes for exit E2 to clear all 264 vehicles, 41 minutes for exit E3 to clear all 196 vehicles, and 39 minutes for exit E4 to clear all 184 vehicles. Vehicles through exit E2 and E4 had a maximum evacuation time, i.e., 58 minutes. Vehicles through exit $\mathrm{E} 2$ had the highest average departure rate, i.e., 6.6 vehicles per minute, while vehicles through exit $\mathrm{E} 4$ had the lowest average departure rate, i.e., 4.7 vehicles per minute.

Additionally, we also calculated the traffic flows of different road segments during the evacuation process. Figure 7 indicates the comparison of traffic flows on every road segment with and without evacuation. It was found that the four road segments connecting the four exits of the parking lot had the largest increase in traffic flows during the evacuation process, while five road segments (C4, C9), $(\mathrm{C} 5, \mathrm{C} 10),(\mathrm{C} 8, \mathrm{C} 13),(\mathrm{C} 2, \mathrm{C} 3)$, and $(\mathrm{C} 15, \mathrm{C} 16)$ had no change in traffic flows because they did not lie on the optimal routes chosen by vehicles. 


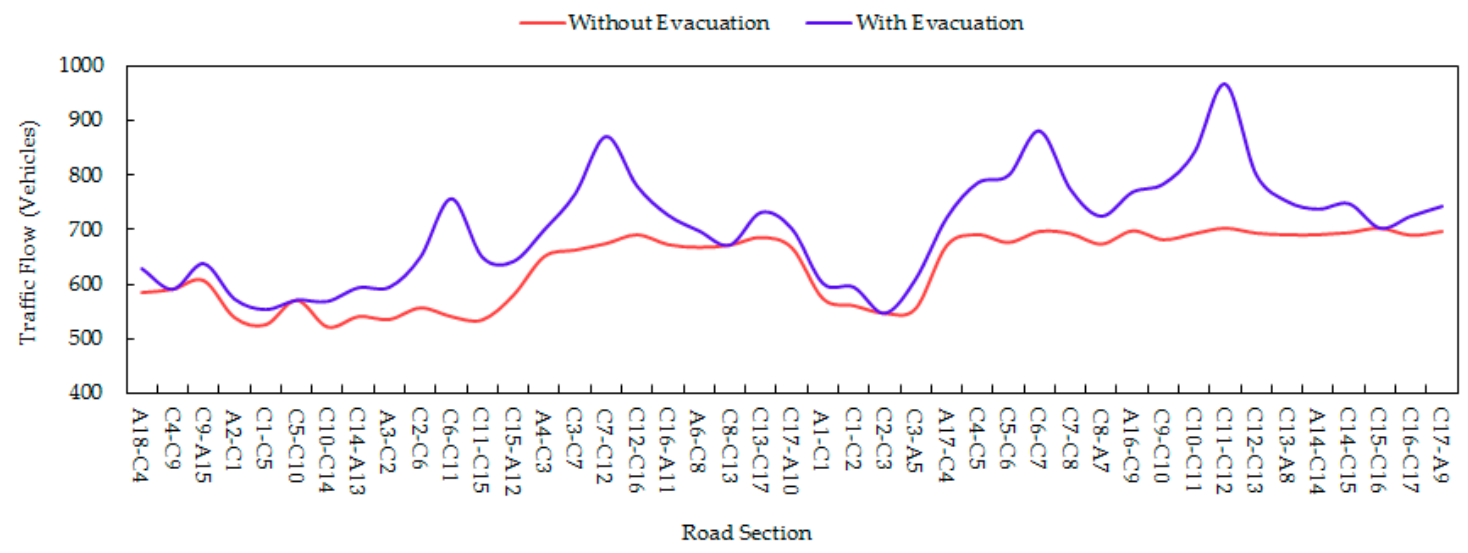

Figure 7. Traffic flows on every road segment with and without evacuation.

\subsubsection{Average Queuing Time and Travel Time}

Besides the evacuation time, we also calculated the average queuing time and average travel time of the vehicles evacuated from each of the four exits of the parking lot, as shown in Figure 8. Due to the higher background traffic flows on links $(\mathrm{C} 6, \mathrm{C} 7)$ and $(\mathrm{C} 7, \mathrm{C} 12)$, the departure rate of vehicles out of exits E3 and E4 was lower, which made these vehicles consume more time in a queuing system, i.e., the average queuing time of queuing systems E3 and E4 was 26.1 minutes and 25.4 minutes, respectively. However, since the evacuation routes from exits E1 and E2 in the buffers had lower background traffic flow volumes, the travel time of vehicles out of these two exits was lower, i.e., the average travel time was 15.8 minutes and 14.7 minutes, respectively.

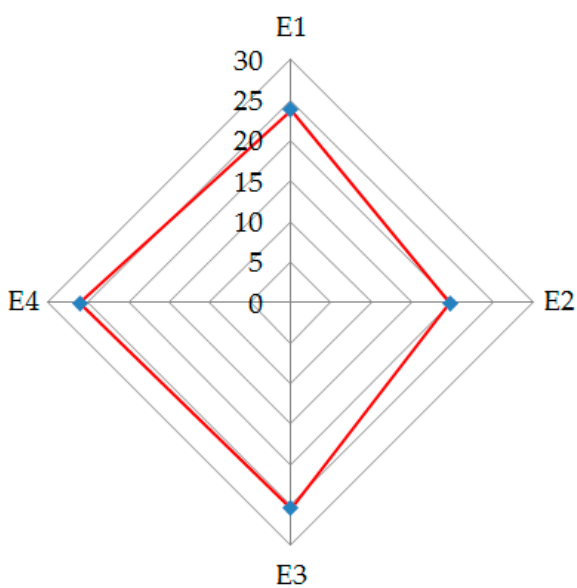

(a)

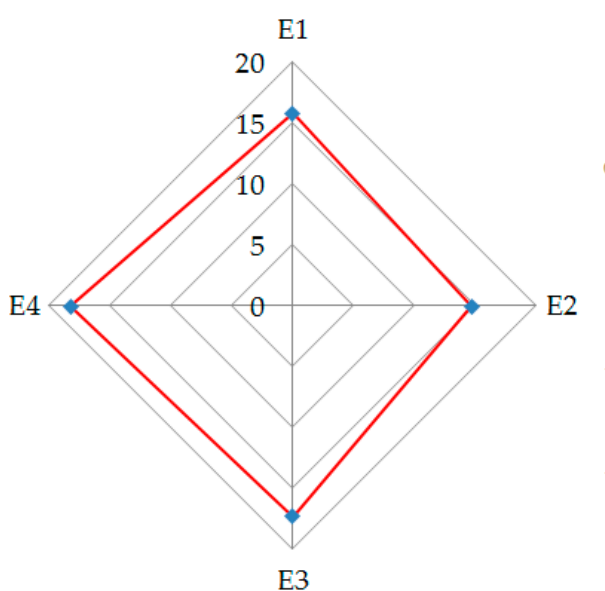

(b)

Figure 8. Average queuing time and average travel time of the vehicles evacuated from the four exits of the parking lot. (a) Average queuing time. (b) Average travel time.

\section{Discussion}

\subsection{Optimal Evacuation Strategy}

Since it is an important part of disaster mitigation and emergency disposal, an optimal evacuation strategy is usually dependent on road network capacities, traffic management equipment, emergency response resources, real-time traffic conditions, etc. Different from previous research [44-46], we divided the evacuation process of a parking lot into two periods. In the first period, a queuing theory was used to estimate the queuing time. In the second period, a traffic flow equilibrium model and an intersection delay model were employed to simulate vehicles' route choice. Compared to the study 
of Zheng et al. [47], we not only estimated the queuing time and travel time but also computed the delay at the intersections. As such, we could obtain a more comprehensive and accurate estimation of total evacuation times. Background traffic flow is always less considered in evacuation problems [48], but it actually has a dynamic impact on the two-period evacuation process of a parking lot. It was found that vehicles' departure rate of every exit is mainly dependent on the time headway of the background traffic flows on the road connecting the exit of the parking lot. We also know that the dynamic distribution of background traffic flows in the evacuation road network influences the optimal evacuation routes greatly; this observation is in line with the study of Alam et al. [49]. Additionally, to our knowledge, the method proposed in this research is an optimization model with minimum evacuation time, which is also applicable in the vehicle evacuation problems of other infrastructures, e.g., tunnels and bridges.

\subsection{Sensitivity Analysis of $\tau_{r}$}

$\tau_{r}$ is the minimum threshold of time headway of the background traffic flows on roads connecting the exits, which allows the vehicles leaving the exits to merge into background traffic flows. Meanwhile, $\tau_{r}$ determines the vehicle departure rate through the exits, and there is a positive relationship between $\tau_{r}$ and the vehicle departure rate. In this section, we analyze the sensitivity of evacuation efficiency relative to the variations of $\tau_{r}$.

We simulated the variations of average queuing time, average travel time, and total evacuation time with different values of $\tau_{r}$, as shown in Figure 9. The higher the $\tau_{r}$ is, the more vehicles can leave the exits during a certain time period. Since a higher $\tau_{r}$ increases the departure rate but also leads to a higher traffic delay on the evacuation routes, there is a negative relationship between average travel time and $\tau_{r}$. While the fluctuation in total evacuation time is an inverted U-shaped curve. $\tau_{r}=6$ is the minimum point for total evacuation time. When $\tau_{r}<6$, the average travel time is the main contribution to the total evacuation time, but a lower $\tau_{r}$ has a higher possibility to bring about traffic accidents. The total evacuation time is mainly affected by the average queuing time when $\tau_{r}>6$. Hence, the optimal value setting of $\tau_{r}$ is a tradeoff between the queuing time and travel time.

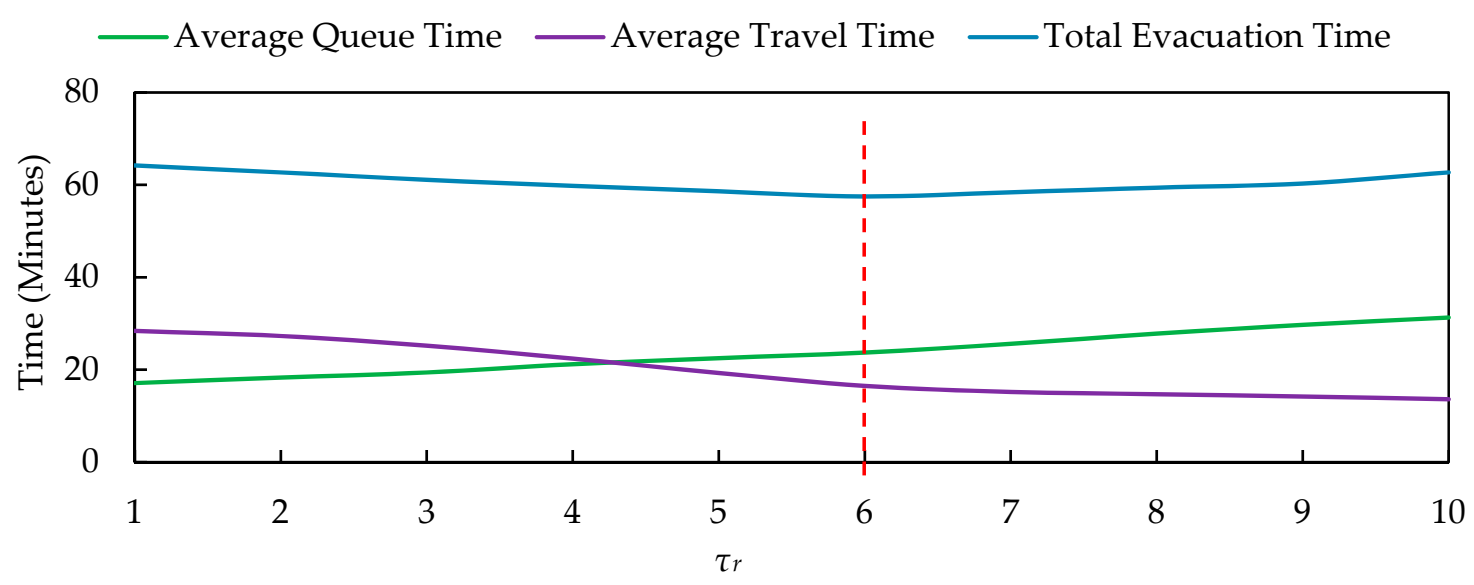

Figure 9. Sensitivity analysis of $\tau_{r}$.

\section{Conclusions}

An optimal evacuation plan for parking lots aims to guide the vehicles from a parking lot following the optimal routes to safe areas with a minimum total evacuation time. In reality, the background traffic flows in a road network always change dynamically over time, and this greatly affects the departure rate of vehicles leaving out of parking lots and determines the optimal evacuation route selection for vehicles. In view of this, this research proposed an optimal evacuation model with total evacuation time minimization using a queuing theory combined with a traffic flow equilibrium model and an intersection delay model. This new model can estimate evacuation time, including queuing 
time and travel time, and can simulate optimal evacuation routes. A modified ant colony algorithm was developed as the model solution. In addition, a numerical example was employed to test the model. The main results are described as follows.

(1) The simulation results of the numerical example indicate that the optimal evacuation model proposed in this research has an advantage in estimating the total evacuation time comprehensively and can generate a dynamic evacuation plan according to the time variation of background traffic flows in a road network.

(2) The results also show that vehicle evacuation for the parking lot is a dynamic process. In other words, the vehicle departure rate in a parking lot has a dynamic time-variation, and the vehicles choose their optimal routes dynamically according to dynamic background traffic flows in the road network.

(3) The sensitivity analysis reveals that the minimum threshold of time headway $\tau_{r}$ has a positive relationship with the average queuing time, a negative relationship with the average travel time, and a U-shaped relationship with the total evacuation time, which means that $\tau_{r}$ has a great impact on optimal evacuation plans.

Due to their importance and necessity, optimal evacuation problems have attracted tremendous attention from lots of researchers. However, the interaction between background traffic flows and evacuation strategy has rarely been investigated. This research intends to provide a reference to improve evacuation efficiency. However, there are two limitations of this research. Firstly, we only focused on a parking lot with single-lane exits instead of multi-lane exits. Secondly, some uncertainties, such as weather conditions affecting travel time and the impact of secondary accidents on route choice, were not involved in this research. These limitations will be investigated in a following work.

Author Contributions: X.M. designed research methods and wrote the manuscript, C.Y. collected and analyzed the data, J.G. edited and revised the manuscript, and J.Z. drew the figures.

Funding: This research was funded by the Humanities and Social Science Research Program of Ministry of Education in China (Grant Number 16XJCZH002) and supported by the Fundamental Research Funds for the Central Universities (Grant Number 310823170657 and 300102238501), the National Natural Science Foundation of China (Grant Number 71701022), the Natural Science Basic Research Plan in Shaanxi Province of China (Grant Number 2018JQ7002), the National Key R \& D project (Grant Number 2017YFC0803906), and the Social Science Major Theoretical and Practical Problems Research Project in Shaanxi province of China (Grant Number 2018Z013).

Conflicts of Interest: The authors declare no conflict of interest.

\section{Symbols}

The following list of symbols is used in this research.

A Number of vehicles in the parking lot

$R \quad$ Number of exits of the parking lot

$r \quad$ Index of the exit and queuing system

$A_{r} \quad$ Number of vehicles in the queuing system $r$

$\bar{d}_{r} \quad$ Average queuing time of queuing system $r$

$\mu_{r} \quad$ Average arrival rate of queuing system $r$

$\lambda_{r} \quad$ Departure rate of queuing system $r$

$Q_{r} \quad$ Background traffic volume on the road connecting $r$ th exit

$\tau_{r} \quad$ Minimum threshold of time headway on the road connecting $r$ th exit

h Time headway 
$P_{r}\left(h>\tau_{r}\right) \quad$ Possibility that the time headway $h$ is more than $\tau_{r}$

$t \quad$ A time period

$N_{\text {interval }} \quad$ Number of intervals $\left(h>\tau_{r}\right)$ during a time period $t$

$T_{r} \quad$ Average time between two consecutive intervals

$T_{Q} \quad$ Sum of all vehicles' queuing time in the parking lot

$V_{1} \quad$ Set of origins of evacuation routes

$V_{2} \quad$ Set of mid-points of evacuation routes

$V_{3} \quad$ Set of destinations of evacuation routes

$s \quad$ Index of origins, $s \in V_{1}$

$g \quad$ Index of destinations, $g \in V_{3}$

$i, j \quad$ Index of nodes, $i, j \in V_{1} \cup V_{2} \cup V_{3}$

$N \quad$ Number of mid-points in the network

M Number of origins in the network

$U \quad$ Number of destinations in the network

$(i, j) \quad$ Index of directed links, $(i, j) \in A, i \rightarrow j$

$c_{i j} \quad$ Traffic capacity of link $(i, j)$

$l_{i j} \quad$ Length of link $(i, j)$

$q_{i j} \quad$ Evacuation traffic flow on link $(i, j)$

$q_{i j}^{*} \quad$ Background traffic flow on link $(i, j)$

$t_{i j} \quad$ Actual travel time on link $(i, j)$

$Q_{s g} \quad$ Evacuation demands from origin $s$ to destination $g$

$K_{s g} \quad$ Set of routes from origin $s$ to destination $g$

$k \quad$ Index of routes, $k \in K_{s g}$

$h_{k}^{\text {sg }} \quad$ Trips on route $k$ from origin $s$ to destination $g$

$\delta_{i j}^{s g, k}$

If link $(i, j)$ lies on the route $k$ from origin $s$ to destination $g, \delta_{i j}^{s g, k}=1$, otherwise, $\delta_{i j}^{s g, k}=0$

$v_{i j 0} \quad$ Free flow speed on link $(i, j)$

$\psi, \xi \quad$ Coefficients

$T_{T} \quad$ Total travel time of all vehicles evacuated

$\bar{D}_{i j} \quad$ Average delay at the intersection $j$ on the route $(i, j)$

$\mu \quad$ Signal cycle time

$\lambda \quad$ Green time ratio

y Degree of saturation

$\omega \quad$ Field calibration coefficient

$T_{D} \quad$ Total intersection delays of vehicles 
Appendix A

Table A1. Data of the road network and traffic volumes.

\begin{tabular}{|c|c|c|c|c|c|c|c|c|c|c|c|c|c|c|c|c|c|}
\hline \multirow{2}{*}{ Road } & \multirow{2}{*}{$\begin{array}{l}\text { Road } \\
\text { Segment }\end{array}$} & \multirow{2}{*}{ Code } & \multirow{2}{*}{$\begin{array}{l}\text { Length } \\
(\mathbf{k m})\end{array}$} & \multirow{2}{*}{$\begin{array}{l}\text { Traffic Capacity } \\
\text { (Vehicle/h) }\end{array}$} & \multirow{2}{*}{$\begin{array}{l}\text { Free Flow } \\
\text { Speed }(\mathrm{km} / \mathrm{h})\end{array}$} & \multicolumn{12}{|c|}{ Traffic Volume (Vehicle/Minute) } \\
\hline & & & & & & 13:00-13:05 & 13:05-13:10 & $13: 10-13: 15$ & 13:15-13:20 & 13:20-13:25 & 13:25-13:30 & 13:30-13:35 & 13:35-13:40 & $13: 40-13: 45$ & $13: 45-13: 50$ & 13:50-13:55 & 13:55-14:00 \\
\hline \multirow{3}{*}{ R1 } & A18-C4 & 1 & 1.3 & 2400 & 80 & 46 & 47 & 49 & 49 & 50 & 51 & 51 & 48 & 48 & 49 & 47 & 50 \\
\hline & C4-C9 & 2 & 1.2 & 2400 & 80 & 45 & 47 & 48 & 50 & 52 & 48 & 47 & 49 & 50 & 51 & 53 & 51 \\
\hline & C9-A15 & 3 & 1.2 & 2200 & 70 & 47 & 50 & 51 & 53 & 55 & 54 & 53 & 49 & 47 & 51 & 48 & 49 \\
\hline \multirow{5}{*}{ R2 } & $\mathrm{A} 2-\mathrm{C} 1$ & 4 & 0.3 & 2400 & 80 & 42 & 42 & 45 & 47 & 46 & 49 & 44 & 46 & 45 & 45 & 43 & 45 \\
\hline & $\mathrm{C} 1-\mathrm{C} 5$ & 5 & 2.5 & 2400 & 80 & 43 & 43 & 45 & 46 & 43 & 41 & 47 & 45 & 43 & 44 & 44 & 42 \\
\hline & $\mathrm{C} 5-\mathrm{C} 10$ & 6 & 1.2 & 2400 & 80 & 45 & 47 & 46 & 50 & 51 & 52 & 55 & 50 & 48 & 45 & 42 & 40 \\
\hline & $\mathrm{C} 10-\mathrm{C} 14$ & 7 & 1.8 & 2200 & 70 & 42 & 44 & 43 & 45 & 46 & 45 & 45 & 46 & 43 & 42 & 40 & 41 \\
\hline & C14-A13 & 8 & 1.1 & 2200 & 70 & 44 & 45 & 46 & 48 & 49 & 48 & 43 & 45 & 42 & 41 & 45 & 45 \\
\hline \multirow{5}{*}{ R3 } & A3-C2 & 9 & 0.7 & 2400 & 80 & 43 & 43 & 45 & 47 & 47 & 48 & 43 & 45 & 43 & 43 & 44 & 45 \\
\hline & $\mathrm{C} 2-\mathrm{C} 6$ & 10 & 2.5 & 2400 & 80 & 41 & 43 & 43 & 45 & 45 & 47 & 46 & 48 & 52 & 53 & 48 & 46 \\
\hline & C6-C11 & 11 & 1.2 & 2200 & 70 & 42 & 43 & 44 & 46 & 47 & 47 & 44 & 46 & 45 & 45 & 45 & 47 \\
\hline & C11-C15 & 12 & 1.8 & 2200 & 70 & 44 & 46 & 47 & 43 & 45 & 45 & 46 & 43 & 42 & 46 & 45 & 43 \\
\hline & C15-A12 & 13 & 1.7 & 2200 & 70 & 50 & 46 & 47 & 47 & 45 & 45 & 47 & 51 & 53 & 49 & 50 & 50 \\
\hline \multirow{5}{*}{ R4 } & A4-C3 & 14 & 0.7 & 2200 & 70 & 52 & 53 & 56 & 55 & 55 & 57 & 55 & 55 & 54 & 54 & 53 & 52 \\
\hline & C3-C7 & 15 & 2.5 & 2200 & 70 & 51 & 53 & 56 & 57 & 59 & 54 & 52 & 53 & 56 & 58 & 58 & 56 \\
\hline & C7-C12 & 16 & 0.8 & 2200 & 70 & 53 & 58 & 57 & 58 & 59 & 60 & 56 & 56 & 54 & 54 & 57 & 53 \\
\hline & C12-C16 & 17 & 1.8 & 2400 & 80 & 53 & 55 & 57 & 56 & 56 & 58 & 62 & 59 & 60 & 61 & 58 & 56 \\
\hline & C16-A11 & 18 & 1.7 & 2400 & 80 & 54 & 55 & 53 & 57 & 58 & 62 & 63 & 57 & 54 & 53 & 55 & 52 \\
\hline \multirow{4}{*}{ R5 } & $\mathrm{A} 6-\mathrm{C} 8$ & 19 & 2.3 & 2000 & 60 & 54 & 54 & 55 & 56 & 57 & 58 & 58 & 56 & 55 & 56 & 56 & 53 \\
\hline & C8-C13 & 20 & 1.2 & 2000 & 60 & 52 & 49 & 53 & 53 & 54 & 57 & 58 & 58 & 60 & 63 & 59 & 56 \\
\hline & C13-C17 & 21 & 1.8 & 2200 & 70 & 54 & 55 & 52 & 56 & 60 & 61 & 64 & 61 & 58 & 57 & 53 & 55 \\
\hline & C17-A10 & 22 & 0.6 & 2200 & 70 & 53 & 52 & 53 & 55 & 57 & 58 & 60 & 62 & 57 & 54 & 52 & 54 \\
\hline \multirow{4}{*}{ R6 } & A1-C1 & 23 & 0.4 & 2200 & 70 & 44 & 46 & 48 & 49 & 50 & 50 & 48 & 48 & 47 & 49 & 47 & 48 \\
\hline & C1-C2 & 24 & 0.7 & 2200 & 70 & 42 & 45 & 44 & 46 & 46 & 48 & 48 & 51 & 49 & 48 & 48 & 46 \\
\hline & $\mathrm{C} 2-\mathrm{C} 3$ & 25 & 0.9 & 2000 & 60 & 45 & 45 & 46 & 47 & 43 & 42 & 44 & 48 & 47 & 49 & 46 & 45 \\
\hline & C3-A5 & 26 & 2 & 2000 & 60 & 43 & 45 & 46 & 47 & 46 & 46 & 46 & 49 & 47 & 48 & 47 & 46 \\
\hline \multirow{6}{*}{ R7 } & A17-C4 & 27 & 0.3 & 2200 & 70 & 53 & 53 & 53 & 55 & 57 & 59 & 60 & 58 & 57 & 57 & 55 & 54 \\
\hline & C4-C5 & 28 & 1.1 & 2200 & 70 & 54 & 56 & 58 & 55 & 60 & 63 & 62 & 58 & 63 & 54 & 52 & 56 \\
\hline & C5-C6 & 29 & 0.7 & 2200 & 70 & 53 & 56 & 53 & 54 & 58 & 61 & 62 & 56 & 57 & 55 & 58 & 54 \\
\hline & C6-C7 & 30 & 0.9 & 2000 & 60 & 55 & 53 & 57 & 58 & 59 & 60 & 61 & 64 & 57 & 58 & 59 & 56 \\
\hline & C7-C8 & 31 & 2.1 & 2000 & 60 & 55 & 57 & 58 & 60 & 60 & 62 & 62 & 57 & 56 & 55 & 58 & 53 \\
\hline & $\mathrm{C} 8-\mathrm{A} 7$ & 32 & 1.1 & 2000 & 60 & 53 & 56 & 57 & 56 & 58 & 55 & 54 & 56 & 57 & 58 & 54 & 60 \\
\hline \multirow{6}{*}{ R8 } & A16-C9 & 33 & 0.3 & 2200 & 70 & 56 & 57 & 54 & 58 & 60 & 62 & 61 & 64 & 58 & 56 & 55 & 57 \\
\hline & C9-C10 & 34 & 1.1 & 2200 & 70 & 54 & 57 & 58 & 60 & 58 & 54 & 53 & 56 & 57 & 59 & 60 & 56 \\
\hline & C10-C11 & 35 & 0.7 & 2200 & 70 & 55 & 57 & 56 & 59 & 59 & 58 & 57 & 60 & 57 & 57 & 58 & 60 \\
\hline & C11-C12 & 36 & 0.9 & 2400 & 80 & 53 & 56 & 58 & 59 & 60 & 63 & 64 & 61 & 57 & 58 & 56 & 58 \\
\hline & $\mathrm{C} 12-\mathrm{C} 13$ & 37 & 2.1 & 2400 & 80 & 55 & 57 & 58 & 55 & 54 & 56 & 60 & 62 & 63 & 58 & 57 & 59 \\
\hline & C13-A8 & 38 & 1.3 & 2400 & 80 & 53 & 56 & 57 & 58 & 55 & 54 & 60 & 61 & 62 & 60 & 58 & 57 \\
\hline \multirow{5}{*}{ R9 } & A14-C14 & 39 & 1 & 2000 & 60 & 54 & 55 & 55 & 53 & 56 & 58 & 58 & 60 & 62 & 63 & 59 & 58 \\
\hline & C14-C15 & 40 & 0.7 & 2000 & 60 & 53 & 56 & 58 & 56 & 57 & 60 & 62 & 61 & 58 & 57 & 60 & 57 \\
\hline & C15-C16 & 41 & 0.9 & 2200 & 70 & 55 & 57 & 58 & 60 & 61 & 558 & 59 & 62 & 63 & 58 & 55 & 57 \\
\hline & C16-C17 & 42 & 2.1 & 2200 & 70 & 54 & 56 & 56 & 57 & 57 & 60 & 59 & 60 & 59 & 58 & 57 & 57 \\
\hline & C17-A9 & 43 & 0.4 & 2200 & 70 & 54 & 56 & 56 & 57 & 60 & 61 & 59 & 59 & 58 & 57 & 62 & 58 \\
\hline
\end{tabular}




\section{References}

1. Zhang, X.; Chang, G.-L. An optimization model for guiding pedestrian-vehicle mixed flows during an emergency evacuation. J. Intell. Transp. Syst. 2014, 18, 273-285. [CrossRef]

2. Pidd, M.; De Silva, F.; Eglese, R. A simulation model for emergency evacuation. Eur. J. Oper. Res. 1996, 90, 413-419. [CrossRef]

3. Pillac, V.; Van Hentenryck, P.; Even, C. A conflict-based path-generation heuristic for evacuation planning. Transp. Res. Part B Methodol. 2016, 83, 136-150. [CrossRef]

4. Rushton, B.T. Low-impact parking lot design reduces runoff and pollutant loads. J. Water Resour. Plan. Manag. 2001, 127, 172-179. [CrossRef]

5. Cova, T.J.; Dennison, P.E.; Drews, F.A. Modeling evacuate versus shelter-in-place decisions in wildfires. Sustainability 2011, 3, 1662-1687. [CrossRef]

6. Dow, K.; Cutter, S.L. Emerging hurricane evacuation issues: Hurricane Floyd and South Carolina. Nat. Hazards Rev. 2002, 3, 12-18. [CrossRef]

7. Fu, H.; Wilmot, C.G.; Zhang, H.; Baker, E.J. Modeling the hurricane evacuation response curve. Transp. Res. Rec. 2007, 2022, 94-102. [CrossRef]

8. Shekhar, S.; Yang, K.; Gunturi, V.M.; Manikonda, L.; Oliver, D.; Zhou, X.; George, B.; Kim, S.; Wolff, J.M.; Lu, Q.; et al. Experiences with evacuation route planning algorithms. Int. J. Geogr. Inf. Sci. 2012, 26, 2253-2265. [CrossRef]

9. Kunwar, B.; Simini, F.; Johansson, A. Evacuation time estimate for total pedestrian evacuation using a queuing network model and volunteered geographic information. Phys. Rev. E 2016, 93, 032311. [CrossRef]

10. Yang, X.; Ban, X.J.; Mitchell, J. Modeling multimodal transportation network emergency evacuation considering evacuees' cooperative behavior. Transp. Res. Part A Policy Pract. 2018, 114, 380-397. [CrossRef]

11. Shiomi, Y.; Taniguchi, T.; Uno, N.; Shimamoto, H.; Nakamura, T. Multilane first-order traffic flow model with endogenous representation of lane-flow equilibrium. Transp. Res. Part C Emerg. Technol. 2015, 59, 198-215. [CrossRef]

12. Xu, S.; Jiang, W.; Deng, X.; Shou, Y. A modified Physarum-inspired model for the user equilibrium traffic assignment problem. Appl. Math. Model. 2018, 55, 340-353. [CrossRef]

13. Maghelal, P.; Peacock, W.G.; Li, X. Evacuating together or separately: Factors influencing split evacuations prior to Hurricane Rita. Nat. Hazards Rev. 2016, 18, 04016008. [CrossRef]

14. Yin, W.; Cordahi, G.; Roden, D.; Wolshon, B. Risk reduction impact of connected vehicle technology on regional hurricane evacuations: A simulation study. Int. J. Disaster Risk Reduct. 2018, 31, 1245-1253. [CrossRef]

15. Shahparvari, S.; Chhetri, P.; Abbasi, B.; Abareshi, A. Enhancing emergency evacuation response of late evacuees: Revisiting the case of Australian Black Saturday bushfire. Transp. Res. Part E Logist. Transp. Rev. 2016, 93, 148-176. [CrossRef]

16. Sheffi, Y.; Mahmassani, H.; Powell, W.B. A transportation network evacuation model. Transp. Res. Part A Gen. 1982, 16, 209-218. [CrossRef]

17. Yamada, T. A network flow approach to a city emergency evacuation planning. Int. J. Syst. Sci. 1996, 27, 931-936. [CrossRef]

18. Cova, T.J.; Johnson, J.P. A network flow model for lane-based evacuation routing. Transp. Res. Part A Policy Pract. 2003, 37, 579-604. [CrossRef]

19. Fang, Z.; Zong, X.; Li, Q.; Li, Q.; Xiong, S. Hierarchical multi-objective evacuation routing in stadium using ant colony optimization approach. J. Transp. Geogr. 2011, 19, 443-451. [CrossRef]

20. Sbayti, H.; Mahmassani, H.S. Optimal scheduling of evacuation operations. Transp. Res. Rec. 2006, 1964, 238-246. [CrossRef]

21. Bretschneider, S.; Kimms, A. A basic mathematical model for evacuation problems in urban areas. Transp. Res. Part A Policy Pract. 2011, 45, 523-539. [CrossRef]

22. Chiu, Y.-C.; Zheng, H. Real-time mobilization decisions for multi-priority emergency response resources and evacuation groups: Model formulation and solution. Transp. Res. Part E Logist. Transp. Rev. 2007, 43, 710-736. [CrossRef] 
23. Tak, S.; Kim, S.; Yeo, H. Agent-based pedestrian cell transmission model for evacuation. Transp. A Transp. Sci. 2018, 14, 484-502. [CrossRef]

24. Murray-Tuite, P.M.; Mahmassani, H.S. Transportation network evacuation planning with household activity interactions. Transp. Res. Rec. 2004, 1894, 150-159. [CrossRef]

25. Lämmel, G.; Chraibi, M.; Wagoum, A.U.K.; Steffen, B. Hybrid multimodal and intermodal transport simulation: Case study on large-scale evacuation planning. Transp. Res. Rec. 2016, 2561, 1-8. [CrossRef]

26. Balakrishna, R.; Wen, Y.; Ben-Akiva, M.; Antoniou, C. Simulation-Based Framework for Transportation Network Management in Emergencies. Transp. Res. Rec. 2008, 2041, 80-88. [CrossRef]

27. Kimms, A.; Maassen, K.-C. Optimization and simulation of traffic flows in the case of evacuating urban areas. OR Spectr. 2011, 33, 571-593. [CrossRef]

28. Chang, J.; Wang, J. Unreliable M/M/1/1 retrial queues with set-up time. Qual. Technol. Quant. Manag. 2018, 15, 589-601. [CrossRef]

29. Idjis, K.; Ourbih-Tari, M.; Baghdali-Ourbih, L. Variance reduction in M/M/1 retrial queues using refined descriptive sampling. Commun. Stat. -Simul. Comput. 2017, 46, 5002-5020. [CrossRef]

30. Zhou, M.; Liu, L.; Chai, X.; Wang, Z. Equilibrium strategies in a constant retrial queue with setup time and the N-policy. Commun. Stat. -Theory Methods 2019. [CrossRef]

31. Lioris, J.; Pedarsani, R.; Tascikaraoglu, F.Y.; Varaiya, P. Platoons of connected vehicles can double throughput in urban roads. Transp. Res. Part C Emerg. Technol. 2017, 77, 292-305. [CrossRef]

32. Ha, D.-H.; Aron, M.; Cohen, S. Time headway variable and probabilistic modeling. Transp. Res. Part C Emerg. Technol. 2012, 25, 181-201. [CrossRef]

33. Üster, H.; Wang, X.; Yates, J.T. Strategic Evacuation Network Design (SEND) under cost and time considerations. Transp. Res. Part B Methodol. 2018, 107, 124-145. [CrossRef]

34. Di Gangi, M.; Cantarella, G.E.; Di Pace, R.; Memoli, S. Network traffic control based on a mesoscopic dynamic flow model. Transp. Res. Part C Emerg. Technol. 2016, 66, 3-26. [CrossRef]

35. Levin, M.W.; Boyles, S.D.; Duthie, J.; Pool, C.M. Demand profiling for dynamic traffic assignment by integrating departure time choice and trip distribution. Comput. -Aided Civ. Infrastruct. Eng. 2016, 31, 86-99. [CrossRef]

36. Mao, X.; Wang, J.; Yuan, C.; Yu, W.; Gan, J. A Dynamic Traffic Assignment Model for the Sustainability of Pavement Performance. Sustainability 2018, 11, 170. [CrossRef]

37. Mao, X.; Yuan, C.; Gan, J. Incorporating Dynamic Traffic Distribution into Pavement Maintenance Optimization Model. Sustainability 2019, 11, 2488. [CrossRef]

38. Wang, J.; Mao, X.; Li, Z.; Moore, A.; Staley, S. Determining the reasonable scale of a toll highway network in China. J. Transp. Eng. 2014, 140, 04014046. [CrossRef]

39. Lee, S.; Wong, S. Group-based approach to predictive delay model based on incremental queue accumulations for adaptive traffic control systems. Transp. Res. Part B Methodol. 2017, 98, 1-20. [CrossRef]

40. Saidi-Mehrabad, M.; Dehnavi-Arani, S.; Evazabadian, F.; Mahmoodian, V. An Ant Colony Algorithm (ACA) for solving the new integrated model of job shop scheduling and conflict-free routing of AGVs. Comput. Ind. Eng. 2015, 86, 2-13. [CrossRef]

41. Afshar, A.; Massoumi, F.; Afshar, A.; Mariño, M.A. State of the art review of ant colony optimization applications in water resource management. Water Resour. Manag. 2015, 29, 3891-3904. [CrossRef]

42. Liu, J.; Yang, J.; Liu, H.; Tian, X.; Gao, M. An improved ant colony algorithm for robot path planning. Soft Comput. 2017, 21, 5829-5839. [CrossRef]

43. Sharma, V.; Grover, A. A modified ant colony optimization algorithm (mACO) for energy efficient wireless sensor networks. Int. J. Light Electron Opt. 2016, 127, 2169-2172. [CrossRef]

44. Jha, M.; Moore, K.; Pashaie, B. Emergency evacuation planning with microscopic traffic simulation. Transp. Res. Rec. 2004, 1886, 40-48. [CrossRef]

45. Kwon, E.; Pitt, S. Evaluation of emergency evacuation strategies for downtown event traffic using a dynamic network model. Transp. Res. Rec. 2005, 1922, 149-155. [CrossRef]

46. Sfeir, G.; Antoniou, C.; Abbas, N. Simulation-based evacuation planning using state-of-the-art sensitivity analysis techniques. Simul. Model. Pract. Theory 2018, 89, 160-174. [CrossRef]

47. Zheng, H.; Chiu, Y.-C.; Mirchandani, P.B.; Hickman, M. Modeling of evacuation and background traffic for optimal zone-based vehicle evacuation strategy. Transp. Res. Rec. 2010, 2196, 65-74. [CrossRef] 
48. Murray-Tuite, P.; Wolshon, B. Evacuation transportation modeling: An overview of research, development, and practice. Transp. Res. Part C Emerg. Technol. 2013, 27, 25-45. [CrossRef]

49. Alam, M.J.; Habib, M.A.; Quigley, K.; Webster, T.L. Evaluation of the Traffic Impacts of Mass Evacuation of Halifax: Flood Risk and Dynamic Traffic Microsimulation Modeling. Transp. Res. Rec. 2018, 2672, 148-160. [CrossRef]

(C) 2019 by the authors. Licensee MDPI, Basel, Switzerland. This article is an open access article distributed under the terms and conditions of the Creative Commons Attribution (CC BY) license (http://creativecommons.org/licenses/by/4.0/). 